\title{
The Building of Relationship between the Taxation Authority and Tax Collector Based on the Principal- Agent Game Theory
}

\author{
Chunzhi Ou \\ School of Public Administration and Policy \\ RenminUniversity of ChinaRUC \\ Beijing, China \\ chunzhiyongyuan@163.com
}

\begin{abstract}
Despite its importance to tax collection and management efficiency,Grassroots tax collection is an understudied topic. This is partly attributable to the "tax collection and management predicament," which arises because costs of tax collection and management are easier to measure than its benefits. In this study,we develop and test one game theory model between leviers and Tax authorities,this model explains the relationship between leviers and the tax authorities. Our findings have three key implications for public managers. First, the efficiency of tax collection can be improved if tax authorities meet and guide the needs of leviers. Second, mutual transformation on publicprivate interest poses more challenges and may require additional effort. Third, the mechanism of rewards and punishments has never worked well.
\end{abstract}

Keywords- interest; utility; game theory; principal-agent theory

\section{INTRODUCTION}

Currently in China, the tax collection and supervision activities are performed by tax collectors, the interests of whom are not always identical with those of the taxation authority. The taxation authority aims to complete the tax collection task and takes it as its fundamental goal to improve the observance of the taxpayers in tax payment. In contrast, the tax collectors have their own pursuit of personal interests and have different values, some pursue power or economic benefits, while others pursue a sense of achievement in work.

As to the study on the law enforcement by the tax collectors, many scholars keep criticizing their selfishness, and urge to establish a strict system to supervise their work. However, this system always has its loopholes. Only if we admit that the tax collectors' pursuit of personal interests is a kind of human nature, and manage to guide their behavior with a sound system, can we be able to fundamentally change the current circumstance where the tax collectors' behavior violates the work goals of the taxation authority.

The hypothesis of the economic man is the basic logic starting point of economic theories. A bureaucrat, in the first place, is a natural individual, and thus has the natural attributes of a human being. The bureaucratic title is his social duty, thus he unavoidably has social attributes. As social attributes cannot totally replace natural attributes, the analysis of the behavior of a bureaucrat cannot be completed without the hypothesis of the economic man. However, Dilulio (1994) believes that the principal-agent model based on the self-interest maximization hypothesis is suitable for explaining such bureaucratic behaviors as indolence and abuse of power for personal gains, but can hardly be applied in explaining the existence of the "principled agents" who work diligently, dedicate themselves silently [1]. Here, to be selfish is to peruse personal gains, while to pursue benefits for others may also possibly be pursuing personal gains in the final analysis. In many cases, altruistic behavior is a smart way of pursuing personal gains in the end. We cannot deny that pursuing benefits for others can develop along with pursuing themself interests, that is to say, the two can be realized at the same time. If we bear such a simple idea that to pursue their gains is all about being selfish, then we would fall into the pit of mechanical thinking. Gordon Tullock believes that the officials who use their power for rentseeking corruption activities is barely concerned with moral issues. James Buchanan holds that, political exchange is an ordinary game, where the political traders are just like the players in the game. Reinganum [2] (1991) was the first to apply the principal-agent theory in the study of the tax collection and payment game, analyzing the behaviors of the taxpayers, professional agencies and the taxation authority, with the aim of addressing the problem of how to encourage the tax personnel to complete the tax collection task. The paper will employ the principal-agent theory to analyze the behaviors of the tax collectors of the taxation authority.

\section{THE RELATIONSHIP BETWEEN THE TAXATION AUTHORITY AND THE TAX COLLECTORS}

\section{A. A Principal-agent Relationship is Formed between the Taxation Authority and the Tax Collectors}

In the general meaning, tax levier refers to the tax authority and the tax collectors, while the two have essential differences in many aspects:

1. The utilities of the tax authority and the tax collectors are different;

2. The tax authority has inadequate and unequal information about how many efforts the tax collectors make and the real condition of the tax sources;

3. The risk preferences of the taxation authority and the tax collectors are different; 
The responsibilities and obligations of the taxation authority and the tax collectors are disproportionate;

5. It is impossible for the taxation authority to consider all possible conditions to set well-fledged regulations to prevent misconduct of the tax collectors. Besides, the tax collectors recognition of such regulations can also influence their choice of behavior.

6. The taxation authority can guide with incentives the tax collectors to collect and submit taxes according to law, so as to comply with the interest demand of the taxation authority.

Based on several points stated above, a principal-agent relationship is formed between the taxation authority and the tax collectors, and the game between the two is a process to find their respective maximum utility, until the point of equilibrium is reached.

\section{B. the Basis for Mutual Benefit between the Taxation Authority and the Tax Collectors}

We all know that, it relies on not only the contract but also cooperation and political deals for the principal to guide the behavior of the agent, so that both parties can obtain satisfying utilities:

1. The behavior of tax collectors can be guided. By working out relevant system to move the point of equilibrium of the game players, the natural instincts can be corrected.

2.The taxation authority and the tax collectors have the motive of striking political deals.

3. The political deal between the two parties can provide both with better conditions.

\section{PRINCIPAL-AGENT GAME}

\section{A. Parameter Hypothess}

Use $\mathrm{i}(\mathrm{i}=1,2)$ to represent the players, record the taxation authority (the principal) as 1 and the tax collector (the agent) as 2. Record strategic space as X and strategic choice as "=". The subjective endeavor of the tax collectors can be measured with a, and the tax source a random variable $\xi$, which obeys certain distribution function with $\mu$ as the mean value and

$\sigma^{2}$ as the variance. The work achievement of the tax collector can be expressed as

$$
X=\alpha+\xi
$$

The tax collector, after making endeavor a, get a return of $-\frac{1}{2} \mathrm{ca}^{2}(\mathrm{c}>0)$, which is a parabola with downward opening. The maximum value of the function can be worked out, which is the apex of the parabola. That is to say, the tax collector can be able to maximize his utility.

The taxation authority, as the principal, may recognize the work performance of the tax collectors, or may not recognize his performance, or partly recognize his performance. Suppose $\alpha$ (a fixed positive constant) is the salary that the tax collector deserves, and $\beta(0 \leq \beta \leq 1)$ is the degree of the taxation authority's recognition of the tax collector's work. Recognizing $(\beta=1)$ and not recognizing $(\beta=0)$ are two extreme conditions. $S_{1}=\left\{s_{11}, s_{12}\right\}=\{$ recognizing, not recognizing $\}$. The taxation authority pays the tax collector work target assessment bonus according to the work performance of the tax collector, which is represented by $\beta x$.

Suppose the income function of the tax collector is $S(x)$,

$$
S(x)=(\alpha+\beta x)(2)
$$

The tax collector, as the agent, may work hard to obtain big bonus, or be slack, "waiting for the earthquake to come to turn over the potatoes onto the ground". $S_{2}=\left\{S_{21}\right.$, $\left.\mathrm{S}_{22}\right\}=\{$ endeavoring, not endeavoring $\}$, adopting a work attitude according to the income.

In such a dynamic game featuring information asymmetry, player 1 (the principal--taxation authority) is to determine $\alpha$ and $\beta$ in the salary contract, while player 2 (the agent -- tax collector) is to determine his effort input a after accepting the salary contract.

Suppose the income function of the taxation authority is $t(x)$

$t(x)=x-S(x)=x-(\alpha+\beta x)=(1-\beta)(\alpha+\xi)-\alpha$

\section{B. Analysis of the Game Process}

Record the income of the players as $\mathrm{u}_{\mathrm{i}}$, Record the income function of player 1 (the principal-- taxation authority) as $u_{1}$, and that of player 2 (the agent -- tax collector) as $u_{2}$. Then the expected income of the taxation authority would be:

$\mathrm{u}_{1}\left(\mathrm{~s}_{11}, \mathrm{~s}_{12}, \mathrm{~s}_{21}, \mathrm{~s}_{22}\right)=(1-\beta)(\alpha+\xi)-\alpha$

and the expected income of the tax collector would be :

$\mathrm{u}_{2}\left(\mathrm{~s}_{11}, \mathrm{~s}_{12}, \mathrm{~s}_{21}, \mathrm{~s}_{22}\right)=(\alpha+\beta x)-\frac{1}{2} \mathrm{ca}^{2}(5)$

This game is a repeated and dynamic one in an infinite period of time. The tax collector would have such expectancy that laziness in performing his duty now would lead to low pay in the future. Just as John Muth [3] and Robert Lucas [4], representatives of the School of Rational Expectations, once pointed out, when having an expectancy on the future situation, one needs to consider the past and also needs to estimate the impact of current events on the future situation, and then would change their behavior according to the expected result. As to the limit of rationality, Simon pointed out when making decisions, instead of the "maximization" principle, which will bring them maximized utility [5]. Therefore, the taxation authority and tax collectors cannot absolutely maximize their rational utility, yet they can discount the future risks under the restraints of the objective conditions, so that they would be able to maximize their rationality and utility. In tax collection and administration practice, the taxation authority is risk neutral while the tax collectors are risk averse. Suppose the risk aversion degree of the tax collector is $\rho$, then the expected income function of the tax collector would be revised 
into: $\mathrm{u}_{2}\left(\mathrm{~s}_{11}, \mathrm{~s}_{12}, \mathrm{~s}_{21}, \mathrm{~s}_{22}\right)$

$$
\begin{aligned}
\alpha+\beta a-\frac{1}{2} c a^{2} & -\frac{1}{2} \rho v a \gamma[S(x)] \\
& =\alpha+\beta a-\frac{1}{2} \mathrm{ca}^{2}-\frac{1}{2} \rho \beta^{2} \sigma^{2}(6)
\end{aligned}
$$

Suppose the retained utility (or opportunity cost) of the tax collector is $w_{0}$, then the sufficient condition for the had work of the tax collector would be:

$$
\alpha+\beta a-\frac{1}{2} \mathrm{ca}^{2}-\frac{1}{2} \rho \beta^{2} \sigma^{2} \geq w_{0}(7)
$$

How much effort need to be made by the tax collector to maximize his utility?

Namely, $\quad a=\frac{\beta}{c}(8)$

$$
\frac{\partial \mathrm{u}_{2}}{\partial \mathrm{a}}=\beta-\mathrm{ca}=0
$$

When the target assessment bonus and the basic salary granted by the taxation authority are just equal to the retained utility of the tax collector, substitute (8) into (6)

$$
\begin{aligned}
& \operatorname{maxu}_{2}\left(\mathrm{~s}_{11}, \mathrm{~s}_{12}, \mathrm{~s}_{21}, \mathrm{~s}_{22}\right) \\
= & \alpha+\beta a-\frac{1}{2} \mathrm{ca}^{2}-\frac{1}{2} \rho \beta^{2} \sigma^{2}-w_{0} \\
= & \alpha+\frac{1}{2} \mathrm{ca}^{2}-\frac{1}{2} \rho \beta^{2} \sigma^{2}-w_{0} \\
= & \frac{\beta}{\mathrm{c}}+\frac{\beta^{2}}{2 \mathrm{c}}-\frac{1}{2} \rho \beta^{2} \sigma^{2}-w_{0}(9)
\end{aligned}
$$

To work out $\beta^{*}$,

$$
\beta^{*}=\frac{\partial \mathrm{u}_{2}}{\partial \beta}=\frac{1}{\mathrm{c} \rho \sigma^{2}-1}(10)
$$

Substitute (10) into (8),

$$
\mathrm{a}^{*}=\frac{1}{\left(\mathrm{c} \rho \sigma^{2}-1\right) \mathrm{c}}(11)
$$

Substitute (10), (11) into (7),

$$
\alpha^{*}=w_{0}+\frac{1}{2 \mathrm{c}\left(\mathrm{c} \rho \sigma^{2}-1\right)}-\frac{1}{\mathrm{c}\left(\mathrm{c} \rho \sigma^{2}-1\right)^{2}}(12)
$$

$\left(w_{0}+\frac{1}{2 \mathrm{c}\left(\mathrm{c} \rho \sigma^{2}-1\right)}-\frac{1}{\mathrm{c}\left(\mathrm{c} \rho \sigma^{2}-1\right)^{2}}, \frac{1}{\mathrm{c} \rho \sigma^{2}-1}\right)$ and $\frac{1}{\left(c \rho \sigma^{2}-1\right) c}$ shows the Perfect Nash equilibrium of the subgame of the game.

\section{Analysis of the game resultt}

$\alpha^{*}$ is the due salary of the tax collector. $\beta^{*} \mathrm{x}$ is the target bonus of tax collector. The bigger the uncertainty in the tax source, namely the bigger $\sigma^{2}$, the higher the risk aversion degree of the tax collector $\rho$, and the lower the taxation authority's recognition of the tax collector's work performance $\beta$. The game between the two parties is a repeated and dynamic one in an infinite period of time. The tax collector has known from the very beginning that to tear up the contract unilaterally is nothing good, so he will consider the risk factors in advance. The sub-game perfect Nash equilibrium solution shows that, when the uncertainty of the tax source is infinitely great, the taxation authority's recognition of the tax collector's work becomes 0 , the tax collector would not work hard any more, yet he still retains utility income $w_{0}$.
The higher the risk aversion degree, the more severe the punishment received for betraying such cooperation, thus the increased confidence level of such cooperation. Obviously, risk aversion degree is a dynamic variable, which varies along with the independent variable. What determines the risk aversion degree of the tax collector? It is the scientific and strict rewards and punishment mechanism.

\section{Test of Practice on the Model}

The tax collection responsibility system released in 2009 marks the great improvement of the tax collection and administration system. We know that the improvement of the tax collection and administration system relies on the advancement of information technology, which will make the misconduct of the tax collectors easily visible.

TheTable 1 shows that the sampling accuracy jumped from around $50 \%$ in 2008 to around $90 \%$ in 2009 , and a law execution responsibility system was set up. In the past, the enterprises can use irregular means to make the tax inspection personnel to turn a blind eye to the illegal act of the enterprises, and the inspection result would be "no problems identified". This would lead to man-made low sampling accuracy, which is not quite the truth actually. Since the law execution responsibility investigation is introduced, the chance for tax collectors to carry out misconduct becomes less, the cost for misconduct bigger and the possibility of exposure of the misconduct increases. All in all, for the tax collector, the law execution behavior is a choice for maximization of personal interests. It can be said that, the tax collection responsibility system set up by the principal has exerted immediate effect on standardizing the law execution behavior of the agent.

\section{E. Reflection on the Model}

In many political debates, it seems that the following progress has been made, "if two or more parties have conflictedinterests, then no consensus would be reached, that is to say, no deal would be stricken. If acts are not restricted, then some interests would become superior over other interests." Such ways of deducing seem to be quite reasonable when considering the daily economic deals faced by an individual. However, the conflict of interests between various parties does not mean that a consensus cannot be reached. In many cases, consensus can be reached despite conflicted interests between parties, when the parties would keep bargaining with each other to find an appropriate compromise. Consensus is the only examination for mutual interests. The game players would find the point of equilibrium.

The taxation authority represents the state to organize the fiscal revenue, and the personal interests of the tax collector seem to have no obvious relations with the state's fiscalrevenue. In private choice, however, he does have such inherent sense of responsibility. Only by encouraging such inherent sense of responsibility to be displayed in the taxcollection work, the tax collectors may possibly work hard. 
Understanding from this perspective, there shall exist such psychological contract between the taxation authority and the tax collector: the work performance of the tax collector is concerned parties. This process of benefiting others is actually a process of pursuing personal interests in the essence. Game equilibrium starts from the purpose of self-serving and finally

\section{TABLE 1 .TAXATION INSPECTION STATEMENT}

\begin{tabular}{|c|c|c|c|c|c|c|c|c|}
\hline & $\begin{array}{l}\text { Number of } \\
\text { taxpayers } \\
\text { inspected } \\
(10,000)\end{array}$ & $\begin{array}{l}\text { Proportion } \\
\text { to the total } \\
\text { taxpayers }\end{array}$ & $\begin{array}{l}\text { Number of } \\
\text { defective } \\
\text { taxpayers }(10,000)\end{array}$ & $\begin{array}{l}\text { Sampling } \\
\text { accuracy }\end{array}$ & $\begin{array}{l}\text { Filling up } \\
\text { upon } \\
\text { inspection (100 } \\
\text { million yuan) }\end{array}$ & $\begin{array}{ll}\text { Filling } & \text { up } \\
\text { into the } \\
\text { fiscal } \\
\text { account }\end{array}$ & $\begin{array}{l}\text { Rate of filling } \\
\text { up into the } \\
\text { fiscal account }\end{array}$ & $\begin{array}{l}\text { Law execution } \\
\text { responsibility } \\
\text { investigation }\end{array}$ \\
\hline 2000 & 325 & $13.3 \%$ & 182 & $56.2 \%$ & 419.4 & 391.9 & $93.4 \%$ & \\
\hline 2001 & 259.7 & $10.6 \%$ & 142.12 & $54.7 \%$ & 408.9 & 370.6 & $90.6 \%$ & \\
\hline 2002 & 206.29 & $8.1 \%$ & 108.99 & $52.8 \%$ & 393.32 & 365.74 & $93 \%$ & \\
\hline 2003 & 150.5 & $5.5 \%$ & 81.3 & $54.7 \%$ & 359.1 & 340.7 & $94.9 \%$ & \\
\hline 2004 & 122.9 & $4.3 \%$ & 67.3 & $54.8 \%$ & 367.6 & 339.2 & $92.3 \%$ & \\
\hline 2005 & 107.6 & $3.5 \%$ & 63.5 & $59 \%$ & 361.3 & 329.8 & $91.3 \%$ & \\
\hline 2006 & 86 & & & & 386.4 & & & \\
\hline 2007 & 53.71 & & & & 430.15 & 387.84 & & \\
\hline 2008 & 40.5 & & 22.9 & $56.5 \%$ & & 513.6 & & \\
\hline 2009 & 31.3 & & 28.5 & $90.9 \%$ & 1192.6 & 1176.1 & $98.6 \%$ & 114631 \\
\hline 2010 & 23.52 & & 22.05 & $93.75 \%$ & 1160.45 & 1139.53 & $98.2 \%$ & 341292 \\
\hline 2011 & 21.21 & & 20.22 & $95.35 \%$ & 957.72 & 923.48 & $96.43 \%$ & 18 万 \\
\hline
\end{tabular}

closely connected with position promotion and bonus, whole idling or discipline-breaking is strictly matched with punishment. Only in this way can the inherent sense of responsibility of the tax collector be encouraged to be displayed in the tax collection work.

Under the current circumstance where the tax collector need not be responsible for the work result, where hard work goes against personal interests, and where the tax collector cannot be fired if he has no fault, the risk aversion degree of the tax collector is very low. The personal behavior of the tax collector often goes against the interests of the taxation authority, and the sense of responsibility for tax collection would be unrealistic to be discussed. Only when the taxation authority and the tax collector perform together a strict and reasonable rewards and punishment mechanism to strike a deal or conduct exchange, only then can the agent truly represent the interests of the principal.

\section{CONCLUSIONS}

The principal-agent model does not tell us that the optimum behavior strategy of the tax collector is to not work hard. Quite the contrary, the model pointed out the decisive factors that can guide the tax collector to work hard. We may set up proper regulations and rules to allow these decisive factors to effectively adjust the work attitude of the tax collector.

The result of the above game model shows that there are two key factors influencing tax collection: the tax source information and rewards and punishments system, and the tax collector's attitude in performing his duty. The utilities of the two parties depend on their interaction, and continuous bargaining and balancing would be made before the final result is achieved, which would reflect the common willing of the helps realize the benefits for all. Therefore, a reasonable and strict rewards and punishments system is based on the recognition of the selfish nature of mankind, and is the most effective way of guiding the tax collectors to behave in line with the public interests of the taxation authority.

\section{REFERENCES}

[1] Dilulio, John D.Jr. Principled Agents: The Cultural Bases of Behavior in a Federal Government Bureaucracy. Journal of Public Administration Research and Theory: J-PART, vol.3 April 1994, pp.277-318

[2] Reinganum Jennifer, Louis Wilde. Equilibrium Enforcement and Compliance in the Presence of Tax Practitioners Journal of Law, Economics, and Organization,vol.1July 1991, pp.163-181

[3] John F. Muth rational expectations and the theory of price movements Econometrica,vol.29 March 1961,pp.315-335

[4] Robert E. Lucas Eexpectations and the Neutrality of Money Journal of Economic Theory,April 1972, pp.103-124

[5] Herbert Simon Models of Man : Social and Rational New York: John Wiley and Sons, Inc. 1957,p.279 